
Kidney
Blood Pressure
Research

Kidney Blood Press Res 2013;38:196-204

DOI: $10.1159 / 000355768$

Published onlıne: Apriा 08, 2014

(C) 2014 S. Karger AG, Basel

www.karger.com/kbr

Accepted: February 20, 2014

$1423-0143 / 14 / 0383-0196 \$ 39.50 / 0$

This is an Open Access article licensed under the terms of the Creative Commons AttributionNonCommercial 3.0 Unported license (CC BY-NC) (www.karger.com/OA-license), applicable to the online version of the article only. Distribution permitted for non-commercial purposes only.

\title{
Quantitative Analysis of Abdominal Aortic Calcification in CKD Patients Without Dialysis Therapy by Use of the Agatston Score
}

\author{
Mitsuru Ichii ${ }^{a}$ Eiji Ishimura ${ }^{b}$ Hideaki Shima $^{a}$ Yoshiteru Ohno $^{a}$ \\ Akinobu Ochia Shinya Nakatani ${ }^{a} \quad$ Akihiro Tsuda ${ }^{a}$ Shoichi Eharac \\ Katsuhito Moria Shinya Fukumoto ${ }^{a}$ Toshihide Naganuma ${ }^{d}$ Yoshiaki Takemoto ${ }^{d}$ \\ Tatsuya Nakatani ${ }^{d}$ Masaaki Inaba ${ }^{a}$
}

aDepartment of Endocrinology, Metabolism and Molecular Medicine; bepartment of Nephrology; 'Department of Cardiovascular Medicine; 'Department of Urology, Osaka City University Graduate School of Medicine, Osaka, Japan

\section{Key Words}

Agatston score - Aortic calcification - Chronic kidney disease - Multi-slice computed tomography

\begin{abstract}
Background/Aim: The aim of the present study was to quantitatively examine factors associated with aortic calcification in non-dialysis CKD patients. Methods: We quantitatively investigated aortic calcification from the renal artery to the bifurcation in 149 non-dialysis CKD patients ( $58 \pm 16$ years; 96 males and 53 females, 48 diabetics; eGFR $40.3 \pm 29.3 \mathrm{ml} / \mathrm{min}$ ), and measured Agatston scores using multi-slice computed tomography. Result: Of 149 patients, aortic calcification was present in 117. In patients with aortic calcification, age $(p<0.001)$, C-reactive protein $(p<0.001)$, and intact-PTH $(p<0.001)$ were significantly higher, estimated glomerular filtration rate (eGFR) was significantly lower $(p<0.001)$, and diabetes was observed more often $(p<0.05)$. In regards to the degree of aortic calcification, the Agatston scores correlated significantly and positively with age $(\rho=0.438, p<0.001)$ and serum phosphate $(\rho=0.208, p=0.024)$, and correlated significantly but negatively with e-GFR $(\rho=-0.353, p<0.001)$. In multiple regression analysis, eGFR was associated significantly and independently with the log [Agatston score] $(\beta=-0.346, p<0.01)$, after adjustment for several confounders including serum phosphate and the presence of diabetes. Conclusions: Hyperphospatemia, chronic inflammation, diabetes, and decreased GFR are associated significantly with the presence of aortic calcification in non-dialysis CKD patients. Decreased eGFR was associated significantly and independently with the quantitative degree of aortic calcification.
\end{abstract}

Copyright (C) 2014 S. Karger AG, Basel

Eiji Ishimura, MD, PhD

Department of Nephrology, Osaka City University Graduate School of Medicine, 1-4-3, Asahi-machi, Abeno-ku, Osaka 545-8585 (Japan)

Tel. +816 6645 3806, Fax +81 66645 3808, E-Mail ish@med.osaka-cu.ac.jp 


\section{Kidney Blood Pressure Research}

Kidney Blood Press Res 2013;38:196-204

\begin{tabular}{l|l}
\hline DOI: $10.1159 / 000355768$ & C 2014 S. Karger AG, Basel
\end{tabular}

Published online: Aprit 08, 2014

www.karger.com/kbr

Ichii/Ishimura/Shima et al: Agatston Score of Aortic Calcification in Non-dialysis CKD

\section{Introduction}

Vascular calcification is common and progressive in chronic kidney disease (CKD) [1], and vascular calcification increases the risk of cardiovascular events [2]. Vascular calcification is one form of arteriosclerosis, and vascular calcification, which has been associated with osteochondrogenic differentiation of vascular smooth muscle cells [3-5], is considered to have some points in common to physiological calcification of the bone. It has been reported that serum phosphate induces vascular smooth muscle cell apoptosis and osteochondrogenic differentiation $[4,6]$, and that serum phosphate levels are considered to be associated with vascular calcification [7-9]. In CKD patients, chronic inflammation and accelerated oxidative stress are common, and can also induce vascular calcification [10-12]. Thus, various factors have also been considered to be associated with vascular calcification [13]. In hemodialysis patients, vascular calcification is often present, and is present at the initiation of dialysis therapy, suggesting that vascular calcification progresses during non-dialysis CKD $[13,14]$. However, the extent to which vascular calcification is advanced with regards to the progression of renal failure remains to be further elucidated. Although quantitative evaluations of coronary artery calcification, using Agatston score by electron beam computed tomography or multi-slice computed tomography, have been reported [7, 15-17], factors associated with aortic calcification in patients with non-dialysis CKD have not been fully elucidated. This is partly due to the fact that there are no well-established methods for the quantitative evaluation of aortic calcification. We hypothesized that aortic calcification quantitatively examined progresses with the advancement of CKD. In the present study, we evaluated aortic calcification by use of the Agatston score, as measured by multi-slice computed tomography, and examined factors associated with the presence and advancement of aortic calcification.

\section{Patients and Methods}

\section{Patients}

All CKD patients in the present study were followed regularly by nephrologists of Osaka City University Hospital for the treatment of CKD, and were admitted to the Hospital, for treatment and education of CKD. None of the patients received phosphate binders or cinacalcet for the treatment of secondary hyperparathyroidism. Patients with malignancy and clinically overt infection were excluded. All patients provided informed consent prior to participation in the present study. This study was approved by the hospital ethics review committee (\#1745 of Osaka City University Hospital).

In this study, hypertension was defined as (1) administration of antihypertensive agents or a history of hypertension, (2) systolic pressure $\geq 140 \mathrm{mmHg}$, or (3) diastolic pressure $\geq 90 \mathrm{mmHg}$, as reported previously [18]. Diabetes mellitus was defined as (1) administration of insulin or oral antidiabetic agents, (2) prior diagnosis according to the Report of the Expert Committee on the Diagnosis and Classification of Diabetes Mellitus of the American Diabetes Association [19].

Serum calcium was corrected by serum albumin, according to the formula: Corrected $\mathrm{Ca}[\mathrm{mg} / \mathrm{dl}]$ $=$ measured $\mathrm{Ca}[\mathrm{mg} / \mathrm{dl}]+(4-$ serum albumin $[\mathrm{g} / \mathrm{dl}])$, when serum albumin was below $4.0 \mathrm{~g} / \mathrm{dl}$. Serum PTH was measured by electrochemiluminescence immunoassay (Elecsys PTH; Roche Diagnostics GmbH, Manheim, Germany). The assay detected $5-4000 \mathrm{pg} / \mathrm{ml}$ of intact PTH, with intra- and interassay coefficients of variation were 2.93 and $3.25 \%$, respectively [18].

\section{Measurement of aortic calcification by multi-slice computed tomography}

Patients were scanned in the supine position in the craniocaudal direction, using a 64-slice CT scanner (Somatom Sensation 64; Siemens Medical Solutions, Forchheim, Germany), in which images were obtained with a $3 \mathrm{~mm}$ single slice thickness. The aorta distal to the renal artery to the bifurcation was examined. Aortic calcification was defined as the volume of 2 adjacent pixels with a CT density of $>130$ Hounsfield units within the distribution of the abdominal aorta. All of the acquired sections of multi-slice computed 


\section{Kidney \\ Blood Pressure Research}

Table 1. Clinical characteristics of all patients, and those of patients with and without aortic calcification (AC)

\begin{tabular}{lcccc}
\hline & $\begin{array}{c}\text { All patients } \\
(\mathrm{n}=149)\end{array}$ & $\begin{array}{c}\text { Patients with AC } \\
(\mathrm{n}=117)\end{array}$ & $\begin{array}{c}\text { Patients without AC } \\
(\mathrm{n}=32)\end{array}$ & $\mathrm{p}$ \\
\hline age (years) & $58 \pm 16$ & $64 \pm 11$ & $36 \pm 14$ & $<0.001$ \\
gender (male / female) & $96 / 53$ & $80 / 37$ & $16 / 16$ & 0.054 \\
diabetes (presence / absence) & $48 / 101$ & $43 / 74$ & $5 / 27$ & 0.023 \\
hypertension (presence / absence) & $93 / 56$ & $88 / 29$ & $5 / 27$ & $<0.001$ \\
eGFR (ml/min/1.73m $)$ & $40.3 \pm 29.3$ & $34.1 \pm 24.9$ & $62.9 \pm 35.0$ & $<0.001$ \\
serum creatinine (mg/dl) & $1.48(0.91-3.35)$ & $1.75(1.1-3.58)$ & $0.89(0.68-1.70)$ & $<0.001$ \\
serum albumin (g/dl) & $3.6 \pm 0.6$ & $3.5 \pm 0.6$ & $3.7 \pm 0.7$ & 0.149 \\
total cholesterol (mg/dl) & $198 \pm 56$ & $199 \pm 59$ & $198 \pm 42$ & 0.944 \\
LDL-cholesterol (mg/dl) & $111 \pm 39$ & $112 \pm 41$ & $107 \pm 30$ & 0.508 \\
CRP (mg/dl) & $0.04(0.02-0.11)$ & $0.05(0.02-0.12)$ & $0.02(0.01-0.05)$ & $<0.001$ \\
hemoglobinA1c (\%) & $5.8 \pm 1.2$ & $5.9 \pm 1.3$ & $5.3 \pm 0.6$ & 0.014 \\
glycated albumin (\%) & $14.3 \pm 4.5$ & $14.8 \pm 4.6$ & $12.3 \pm 3.4$ & 0.008 \\
corrected calcium (mg/dl) & $9.2 \pm 0.5$ & $9.2 \pm 0.6$ & $9.3 \pm 0.5$ & 0.419 \\
phosphate (mg/dl) & $4.1 \pm 1.0$ & $4.1 \pm 1.0$ & $3.8 \pm 0.5$ & 0.071 \\
i-PTH (pg/ml) & $48(29.5-106.5)$ & $51(33-110.5)$ & $27.5(20.2-49.2)$ & $<0.001$ \\
smoking (yes / no) & $52 / 97$ & $51 / 67$ & $1 / 31$ & $<0.001$ \\
Agatston score & $502.3(4.6-2070.6)$ & $1021.9(152.2-2918.1)$ & 0 & - \\
\hline Data are expressen
\end{tabular}

Data are expressed as the mean \pm SD or median $\left(25^{\text {th }}-75^{\text {th }}\right)$. e-GFR: estimated glomerular filtration rate, LDL-cholesterol: low density lipoprotein cholesterol, CRP: C-reactive protein, i-PTH: intact parathyroid hormon

tomography were then reviewed by an experienced investigator who was blinded to the clinical data. The intraobserver correlation was 0.99 [20]. The quantitative aortic calcification was calculated according to the method described by Agatston et al [21].

\section{Statistical analysis}

All data are expressed as the mean \pm SD or median $\left(25^{\text {th }}-75^{\text {th }}\right)$. Differences between groups were examined by unpaired Student's t-test or Mann Whitney U test. Categorical variables were compared using $\chi^{2}$ test or Fisher's exact test. Agatston scores were compared among the patients at each of the CKD stages with one-way ANOVA followed by post-hoc Scheffé tests. In multiple regression analyses, the Agatston score was logarithmically transformed as a dependent variable. Gender, diabetes mellitus, current smoker and hypertension were represented by dummy variables ( $0=$ male, $1=$ female, $0=$ absence, $1=$ presence $)$. A $p$-value $<0.05$ was considered statistically significant. These analyses were determined on a Windows computer using the Stat View V Statistical System (SAS Institute, Cary, NC).

\section{Result}

Clinical parameters of the patients

In Table 1, the clinical parameters of the patients who participated in the present study are shown. The mean ( \pm SD) age was $58 \pm 16$ years. Of the 149 patients, there were 96 males and 53 females, and $48(33.2 \%)$ had diabetes mellitus. The mean ( \pm SD) eGFR was $40.3( \pm$ 29.3) $\mathrm{ml} / \mathrm{min} / 1.73 \mathrm{~m}^{2}$. The median $\left(25^{\text {th }}-75^{\text {th }}\right)$ intact PTH was $48(29.5-106.5) \mathrm{pg} / \mathrm{ml}$.

\section{Presence of aortic calcification}

Of the 149 patients, aortic calcification with an Agatston score $>0$ was detected in 117 $(78.5 \%)$, and the remaining 32 exhibited no aortic calcification (Agatston score $=0$ ). As shown in Table 1, the patients with aortic calcification were significantly older than those without ( $\mathrm{p}<0.001)$, and aortic calcification was found more often $(\mathrm{p}=0.023)$ in diabetic patients. Aortic calcification was more frequently observed in patients with a history of hypertension $(\mathrm{p}<0.001)$. Serum creatinine was significantly higher in patients with aortic calcification than in those without $(\mathrm{p}<0.001)$, and eGFR was significantly lower in the former than in the latter group ( $\mathrm{p}<0.001)$. C-reactive protein (CRP) was significantly higher 


\section{Kidney \\ Blood Pressure Research}

Kidney Blood Press Res 2013;38:196-204

\begin{tabular}{l|l}
\hline DOI: $10.1159 / 000355768$ & (c) 2014 S. Karger AG, Basel
\end{tabular}

www.karger.com $/ \mathrm{kbr}$

199 in patients with aortic calcification than in those without $(\mathrm{p}<0.001)$. HemoglobinA1c and glycated albumin were significantly higher in the former than in the latter group ( $p=0.014$ and $p=0.008$, respectively). Intact PTH was significantly higher in the former than in the latter group $(\mathrm{p}<0.001)$.

Correlations between the Agatston score and clinical parameters in patients with aortic calcification (Agatston score $>0$ ).

The correlations between the Agatston score and clinical parameters in patients with Agatston scores $>0$ are shown in Table 2. Agatston score correlated significantly and positively with age $(\rho=0.438, p<0.001)$, serum creatinine $(\rho=0.318, p<0.001)$, and serum phosphate $(\rho=0.208, p=0.024)$, and correlated significantly and negatively with eGFR $(\rho=-0.353, \mathrm{p}<0.001)$ (Figure $1 \mathrm{a}$ ).
Table 2. Correlation between Agatston score and with clinical parameters in patients with Agatston score $>0$ (Spearman rank correlation) $(\mathrm{n}=117)$

\begin{tabular}{lcc}
\hline & $\rho$ & $\mathrm{P}$ \\
\hline age (years) & 0.438 & $<0.001$ \\
eGFR $\left(\mathrm{ml} / \mathrm{min} / 1.73 \mathrm{~m}^{2}\right)$ & -0.353 & $<0.001$ \\
serum creatinine $(\mathrm{mg} / \mathrm{dl})$ & 0.318 & $<0.001$ \\
serum albumin $(\mathrm{g} / \mathrm{dl})$ & 0.075 & 0.416 \\
total cholesterol $(\mathrm{mg} / \mathrm{dl})$ & -0.208 & 0.024 \\
LDL-cholesterol $(\mathrm{mg} / \mathrm{dl})$ & -0.292 & 0.001 \\
CRP $(\mathrm{mg} / \mathrm{dl})$ & 0.017 & 0.850 \\
hemoglobinA1c $(\%)$ & 0.007 & 0.942 \\
glycated albumin $(\%)$ & 0.120 & 0.215 \\
corrected calcium $(\mathrm{mg} / \mathrm{dl})$ & -0.010 & 0.916 \\
phosphate $(\mathrm{mg} / \mathrm{dl})$ & 0.208 & 0.024 \\
i-PTH $(\mathrm{pg} / \mathrm{ml})$ & 0.094 & 0.329 \\
\hline
\end{tabular}

$\rho$ : Spearman correlation coefficient. e-GFR: estimated glomerular filtration rate, LDL-cholesterol: low density lipoprotein cholesterol, CRP: C-reactive protein, i-PTH: intact parathyroid hormone
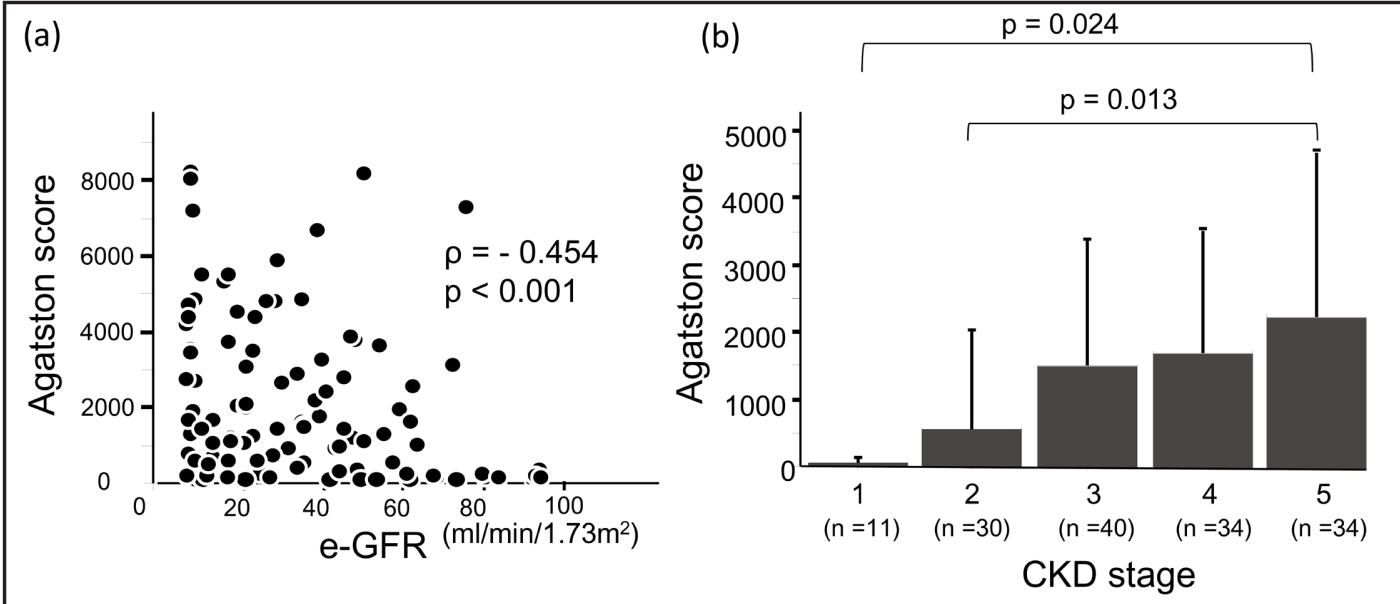

Fig. 1. (a) Correlation between Agatston score and estimated glomerular filtrate rate (eGFR). Agatston score correlated significantly with e-GFR $(\rho=-0.454, \mathrm{p}<0.001)$ by Spearman rank correlation. (b) Agatston score according to each stage of chronic kidney disease (CKD). Agatston score increased as the CKD stages advanced. Agatston scores of CKD stage 5 were significantly higher than those with CKD stage 1 and 2.

As shown in Figure $1 \mathrm{~b}$, Agatston scores increased according with advances in the CKD stages. The Agatston scores of CKD stage 5 were significantly higher than those of CKD stages 1 and $2(\mathrm{p}=0.024$ and $\mathrm{p}=0.013$, respectively).

\section{Independent association with Agatston score in patients with aortic calcification (Agatston} score $>0$ )

We performed multiple regression analyses to investigate whether the Agatston score was associated with eGFR, serum phosphate and log [intact PTH], in patients with Agatston scores $>0$, after adjustment for age, gender, diabetes mellitus, hypertension, log [CRP] and smoking (Table 3). In the analyses, the Agatston score was logarithmically transformed as 


\section{Kidney Blood Pressure Research}

Table 3. Factors associated with log [Agatston score] in patients with Agatston score $>0$ (multiple regression analysis) ( $\mathrm{n}=117)$

\begin{tabular}{|c|c|c|c|c|c|c|c|c|c|c|}
\hline & \multicolumn{2}{|c|}{ Model 1} & \multicolumn{2}{|c|}{ Model 2} & \multicolumn{2}{|c|}{ Model 3} & \multicolumn{2}{|c|}{ Model 4} & \multicolumn{2}{|c|}{ Model 5} \\
\hline & B & $\mathrm{P}$ & $\beta$ & $\mathrm{p}$ & $\beta$ & $\mathrm{p}$ & $\beta$ & $\mathrm{p}$ & $\beta$ & $\mathrm{p}$ \\
\hline age & $\begin{array}{c}0.475 \\
-\end{array}$ & $<0.001$ & 0.437 & $<0.001$ & 0.477 & $<0.001$ & 0.439 & $<0.001$ & 0.373 & $<0.001$ \\
\hline $\begin{array}{l}\text { gender } \\
\text { diabetes }\end{array}$ & 0.009 & 0.915 & -0.006 & 0.938 & -0.002 & 0.981 & -0.031 & 0.738 & 0.019 & 0.825 \\
\hline mellitus & 0.063 & 0.460 & 0.038 & 0.647 & 0.046 & 0.583 & 0.063 & 0.498 & 0.045 & 0.611 \\
\hline hypertension & 0.086 & 0.344 & - & 0.998 & 0.052 & 0.574 & 0.070 & 0.485 & -0.007 & 0.941 \\
\hline $\log \mathrm{CRP}$ & 0.034 & 0.672 & - & 0.998 & 0.040 & 0.618 & 0.027 & 0.757 & 0.012 & 0.883 \\
\hline smoking & 0.191 & 0.042 & 0.161 & 0.078 & 0.189 & 0.043 & 0.208 & 0.040 & 0.137 & 0.165 \\
\hline e-GFR & & & -0.261 & 0.003 & & & & & -0.346 & 0.004 \\
\hline phosphate & & & & & 0.147 & 0.046 & & & 0.127 & 0.220 \\
\hline $\log [\mathrm{i}-\mathrm{PTH}]$ & & & & & & & 0.035 & 0.711 & -0.211 & 0.064 \\
\hline $\mathrm{R}^{2}$ & \multicolumn{2}{|c|}{0.276} & \multicolumn{2}{|c|}{0.333} & \multicolumn{2}{|c|}{0.295} & \multicolumn{2}{|c|}{0.217} & \multicolumn{2}{|c|}{0.301} \\
\hline $\mathrm{P}$ & \multicolumn{2}{|c|}{$<0.001$} & \multicolumn{2}{|c|}{$<0.001$} & \multicolumn{2}{|c|}{$<0.001$} & \multicolumn{2}{|c|}{$<0.001$} & \multicolumn{2}{|c|}{$<0.001$} \\
\hline
\end{tabular}

$\beta$ : standard regression coefficient, $\mathrm{R}^{2}$ : multiple coefficient of determination, CRP: C-reactive protein, e-GFR:

estimated glomerular filtration rate, i-PTH: intact parathyroid hormone

a dependent variable. eGFR and serum phosphate were associated significantly with log [Agatston score] $(\beta=-0.261, p=0.003 ; \beta=0.147, p=0.046$, respectively) after the adjustment (model 2 and model 3, respectively) $\left(\mathrm{R}^{2}=0.333, \mathrm{p}<0.001 ; \mathrm{R}^{2}=0.295, \mathrm{p}<0.001\right.$, respectively). However, log [intact PTH] was not associated with log [Agatston score] after the adjustment (model 4). Furthermore, eGFR was associated significantly and independently with log [Agatston score] $(\beta=-0.346, p=0.004)$ even after adjustment for age, gender, diabetes mellitus, hypertension, log [CRP], smoking, serum phosphate, and log [i-PTH] (model 5) ( ${ }^{2}$ $=0.301, \mathrm{p}<0.001$ ).

\section{Discussion}

In the present study, we quantitatively examined aortic calcification from the region distal to the renal artery to the bifurcation in patients with CKD by use of the Agatston score, as measured by multi-slice computed tomography. In regard to the presence of aortic calcification (Agatston score $>0$ ), compared with the absence of aortic calcification (Agatston score $=0$ ), we found that aortic calcification was observed significantly more often in older patients, diabetic patients, those with hypertension, and those with higher serum creatinine, higher hemoglobinA1c, higher glycated albumin, and higher intact PTH. eGFR was significantly lower in patients with aortic calcification. As the CKD stages advanced, the Agatston scores increased significantly. In regards to the degree or advancement of aortic calcification in patients with Agatston score $>0$, the Agatston score correlated significantly and positively with age, serum creatinine, and serum phosphate and correlated significantly and negatively with eGFR. Multiple regression analyses revealed that higher age and lower eGFR were significantly and independently associated with higher Agatston scores. To our knowledge, this is the first study, in which aortic calcification was quantified by use of Agatston scores in non-dialysis CKD patients.

Several previous studies have evaluated aortic calcification, but relatively few actually focused on non-dialysis CKD patients. Kauppila et al. semi-quantitatively evaluated abdominal aortic calcification using lateral lumbar X-ray films, applying scores of 0 to 3 from the posterior to anterior wall of each vertebral segment [22]. In hemodialysis patients, Adragao et al. reported the semi-quantitative evaluation of arterial calcification of the pelvis and hands using X-ray films [23]. We previously evaluated abdominal aortic calcification by plain lateral abdominal X-ray film [24]. Using plain computed tomography, 


\section{Kidney Blood Pressure Research}

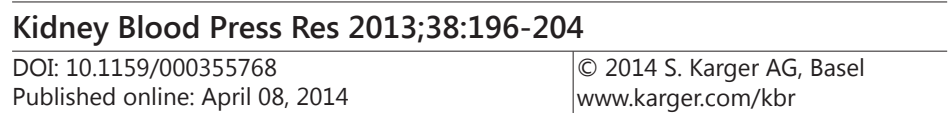

Published onlıne: April 08, 2014 www.karger.com/kbr

Ichii/Ishimura/Shima et al: Agatston Score of Aortic Calcification in Non-dialysis CKD

we semi-quantitatively evaluated indicators of aortic calcification [25]. These methods are complicated to perform and calculate, and not quantitatively precise. The Kidney Disease Improving Global Outcomes (KDIGO) guidelines suggest the evaluation of abdominal calcification in patients with CKD stages 3 to 5 [26]. All of these reports implemented qualitative or semi-quantitative assessments of aortic and arterial calcification, using plain X-ray films or computed tomography, but did not use quantitative methods. In regards to coronary artery calcification, quantitative evaluations, using Agatston score by electron beam computed tomography or multi-slice computed tomography, have been reported, and factors associated with coronary artery calcification have been examined [7, 15-17]. In previous studies analyzing Agatston score of the coronary arteries, an Agatston score $>400$ has been considered to be severe $[15,16]$. Since there has not been any study in which aortic calcification was examined by use of the Agatston score, we cannot determine the significant value for severe aortic calcification from the present study. In the present study, aortic calcification from distal to the renal artery to the bifurcation was examined quantitatively in non-dialysis CKD patients, using the Agatston score as measured by multi-slice computed tomography, and factors associated with both the presence and degree of aortic calcification were evaluated.

In previous studies analyzing factors associated with the presence of vascular calcification, older patients, patients with diabetes, hypertension, smoking and chronic inflammation have been reported to exhibit advanced vascular calcification [25, 27-29]. Merjanian et al. reported that CKD patients with diabetes mellitus exhibit more severe vascular calcification [30]. We reported previously that chronic inflammation was associated with the presence of vascular calcification in hemodialysis patients, using plain X-ray film $[12,24]$. Similar to these reports, in the present study, age was significantly higher in patients with aortic calcification; CRP was significantly higher; diabetes, hypertension and a history of smoking were observed significantly more often in patients with aortic calcification.

In the present study, we further analyzed the factors associated with the degree or advancement of aortic calcification, i.e., advancement of aortic calcification measured by Agatston scores. For the advancement of aortic calcification, diabetes, hypertension and CRP were not significant factors in multiple regression analysis after adjustment for the confounders of age, gender, and smoking. Serum phosphate is well known to be a risk factor of vascular calcification in hemodialysis patients [7]. Hyperphosphatemia induces differentiation of vascular smooth muscle cells into osteoblasts, as well as apoptosis [4]. In the present study, there were significant positive correlations with serum phosphate and Agatston scores. In multiple regression analysis, serum phosphate was significantly and independently associated with the advancement of aortic calcification in the analysis of model 3, which did not include eGFR; however, serum phosphate was not a significant factor associated with the advancement of aortic calcification in the analysis of model 5, in which eGFR was included as a confounder. This finding may suggest that higher serum phosphate was associated with aortic calcification through decreases in eGFR. In the multiple regression analysis of model 5, where all factors were included, eGFR remained a significant factor associated with the advancement of aortic calcification, as assessed by Agatston scores. This finding may suggest that decreases in renal function, itself, or some unknown factors associated with decreased renal function, may be associated with the advancement of aortic calcification.

In recent studies, it has been reported that fibroblast growth factor 23 (FGF23), which is elevated during the early stages of CKD, and serum Klotho, which is decreased in patients with CKD, are both associated with vascular calcification [31]. Klotho-deficient mice exhibit a syndrome that includes a short life span, atherosclerosis and soft-tissue calcification, particularly vascular calcification [32]. Klotho is also capable of directly inhibiting phosphateinduced calcification of vascular smooth muscle cells in vitro [33]. Shoppet et al. reported that FGF23 was associated with advanced aortic calcification in healthy men [34]. Although we could not determine the mechanism by which decreased eGFR, itself, was significantly 


\section{Kidney \\ Blood Pressure Research}

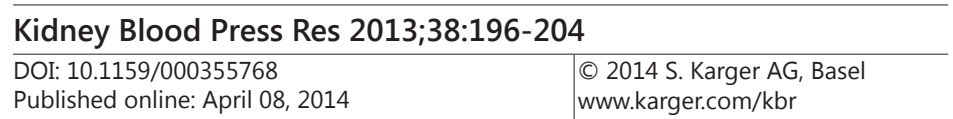

and independently associated with the degree of abdominal aortic calcification, factors that can be altered from the early stage of CKD, such as elevation of FGF23 or decreases in Klotho, may cause advancement of aortic calcification. Possible factors that may be associated with vascular calcification, i.e., serum FGF23 and Klotho, should be examined in future investigations.

There are some limitations in the present study. First, evaluation using multi-slice computed tomography did not allow the evaluation of early-stage, minute calcification. This method also did not allow any distinction between intimal and medial vascular calcification. Differences have been reported in the mechanisms and clinical implications of intimal and medial vascular calcification [35, 36]. However, aortic calcification is considered to be a mixture of both intimal and medial calcification [36]. Our method of multi-slice computed tomography is able to measure total intimal and medial calcification. Secondly, we could not compare the Agatston scores of abdominal aortic calcification with the previous qualitative or semi-quantitative methods of evaluation of aortic calcification as described above. This is partly due to the fact that previous semi-quantitative methods [22-25] are complicated to perform and calculate. It is extremely difficult to validate qualitative, semi-quantitative and qualitative measurements. We believe that our method of measuring Agatston scores for the quantitative assessment of abdominal aortic calcification is comparatively easier and more precise than the previous semi-quantitative methods. Thirdly, we could not analyze factors associated with the Agatston scores separately according to CKD stage, due to the relatively small numbers of patients in each CKD stage. Forthly, because of the cross-sectional nature of the study, the association between several factors and the presence or advancement of abdominal aortic calcification does not necessarily indicate causality, i.e., it remains unknown whether low eGFR directly or indirectly leads to the presence or advancement of aortic calcification. Other possible factors which may be associated with vascular calcification in CKD patients, for example serum FGF23 and Klotho, are necessary to be measured in the future study.

\section{Conclusion}

We quantified abdominal aortic calcification in non-dialysis CKD patients using the Agatston score. We found that lower eGFR was associated significantly with the presence of aortic calcification, and that decreased eGFR was significantly and independently associated with quantitative advancement of aortic calcification after adjustment for various confounders, including age, diabetes, CRP and serum phosphate. Further studies are needed to explore what factors are responsible or causative for advancing aortic calcification in patients with decreased renal function.

\section{Conflicts of Interests}

None declared.

\section{References}

1 Temmar M, Liabeuf S, Renard C, Czernichow S, Esper NE, Shahapuni I, Presne C, Makdassi R, Andrejak M, Tribouilloy C, Galan P, Safar ME, Choukroun G, Massy Z: Pulse wave velocity and vascular calcification at different stages of chronic kidney disease. J Hypertens 2010;28:163-169.

-2 Raggi P, Boulay A, Chasan-Taber S, Amin N, Dillon M, Burke SK, Chertow GM: Cardiac calcification in adult hemodialysis patients. A link between end-stage renal disease and cardiovascular disease? J Am Coll Cardiol 2002;39:695-701. 


\section{Kidney \\ Blood Pressure Research}

\begin{tabular}{l|l}
\hline Kidney Blood Press Res 2013;38:196-204 \\
\hline DOI: 10.1159/000355768 & $\begin{array}{l}\text { () 2014 S. Karger AG, Basel } \\
\text { www.karger.com/kbr }\end{array}$ \\
\hline Published onlIne: April 08, 2014 &
\end{tabular}

Ichii/Ishimura/Shima et al: Agatston Score of Aortic Calcification in Non-dialysis CKD

3 Shao JS, Cai J, Towler DA: Molecular mechanisms of vascular calcification: Lessons learned from the aorta. Arterioscler Thromb Vasc Biol 2006;26:1423-1430.

4 Jono S, McKee MD, Murry CE, Shioi A, Nishizawa Y, Mori K, Morii H, Giachelli CM: Phosphate regulation of vascular smooth muscle cell calcification. Circ Res 2000;87:E10-E17.

5 Bostrom KI: Cell differentiation in vascular calcification. Z Kardiol 2000;89:69-74.

6 Son BK, Akishita M, Iijima K, Eto M, Ouchi Y: Mechanism of pi-induced vascular calcification. J Atheroscler Thromb 2008;15:63-68.

7 Cancela AL, Santos RD, Titan SM, Goldenstein PT, Rochitte CE, Lemos PA, dos Reis LM, Graciolli FG, Jorgetti V, Moyses RM: Phosphorus is associated with coronary artery disease in patients with preserved renal function. PLoS One 2012; 7:e36883.

-8 Goodman WG, Goldin J, Kuizon BD, Yoon C, Gales B, Sider D, Wang Y, Chung J, Emerick A, Greaser L, Elashoff RM, Salusky IB: Coronary-artery calcification in young adults with end-stage renal disease who are undergoing dialysis. N Engl J Med 2000;342:1478-1483.

-9 Ishimura E, Okuno S, Kitatani K, Kim M, Shoji T, Nakatani T, Inaba M, Nishizawa Y: Different risk factors for peripheral vascular calcification between diabetic and non-diabetic haemodialysis patients--importance of glycaemic control. Diabetologia 2002;45:1446-1448.

10 Massy ZA, Stenvinkel P, Drueke TB: The role of oxidative stress in chronic kidney disease. Semin Dial 2009;22:405-408.

11 Ruan XZ, Moorhead JF, Tao JL, Ma KL, Wheeler DC, Powis SH, Varghese Z: Mechanisms of dysregulation of low-density lipoprotein receptor expression in vascular smooth muscle cells by inflammatory cytokines. Arterioscler Thromb Vasc Biol 2006;26:1150-1155.

12 Ishimura E, Okuno S, Kitatani K, Maekawa K, Izumotani T, Yamakawa T, Jono S, Shoji T, Shioi A, Inaba M, Massry SG, Nishizawa Y: C-reactive protein is a significant predictor of vascular calcification of both aorta and hand arteries. Semin Nephrol 2004;24:408-412.

13 Thompson B, Towler DA: Arterial calcification and bone physiology: Role of the bone-vascular axis. Nat Rev Endocrinol 2012;8:529-543.

14 Taniwaki H, Ishimura E, Matsumoto N, Emoto M, Inaba M, Nishizawa Y: Relations between ace gene and ecnos gene polymorphisms and resistive index in type 2 diabetic patients with nephropathy. Diabetes Care 2001;24:1653-1660.

15 Koukoulaki M, Papachristou E, Kalogeropoulou C, Papathanasiou M, Zampakis P, Vardoulaki M, Alexopoulos D, Goumenos DS: Increased prevalence and severity of coronary artery calcification in patients with chronic kidney disease stage iii and iv. Nephron Extra 2012;2:192-204.

16 Watanabe R, Lemos MM, Manfredi SR, Draibe SA, Canziani ME: Impact of cardiovascular calcification in nondialyzed patients after 24 months of follow-up. Clin J Am Soc Nephrol 2010;5:189-194.

17 Braun J, Oldendorf M, Moshage W, Heidler R, Zeitler E, Luft FC: Electron beam computed tomography in the evaluation of cardiac calcification in chronic dialysis patients. Am J Kidney Dis 1996;27:394-401.

18 Shima H, Ishimura E, Naganuma T, Yamazaki T, Kobayashi I, Shidara K, Mori K, Takemoto Y, Shoji T, Inaba M, Okamura M, Nakatani T, Nishizawa Y: Cerebral microbleeds in predialysis patients with chronic kidney disease. Nephrol Dial Transplant 2010;25:1554-1559.

19 Report of the expert committee on the diagnosis and classification of diabetes mellitus. Diabetes Care 2003;26:S5-S20.

20 Ehara S, Shirai N, Okuyama T, Matsumoto K, Matsumura Y, Yoshiyama M: Absence of left ventricular concentric hypertrophy: A prerequisite for zero coronary calcium score. Heart Vessels 2011;26:487-494.

21 Agatston AS, Janowitz WR, Hildner FJ, Zusmer NR, Viamonte M Jr., Detrano R: Quantification of coronary artery calcium using ultrafast computed tomography. J Am Coll Cardiol 1990;15:827-832.

22 Kauppila LI, Polak JF, Cupples LA, Hannan MT, Kiel DP, Wilson PW: New indices to classify location, severity and progression of calcific lesions in the abdominal aorta: A 25-year follow-up study. Atherosclerosis 1997;132:245-250.

23 Adragao T, Pires A, Lucas C, Birne R, Magalhaes L, Goncalves M, Negrao AP: A simple vascular calcification score predicts cardiovascular risk in haemodialysis patients. Nephrol Dial Transplant 2004;19:1480-1488.

24 Okuno S, Ishimura E, Kitatani K, Fujino Y, Kohno K, Maeno Y, Maekawa K, Yamakawa T, Imanishi Y, Inaba M, Nishizawa Y: Presence of abdominal aortic calcification is significantly associated with all-cause and cardiovascular mortality in maintenance hemodialysis patients. Am J Kidney Dis 2007;49:417-425. 


\section{Kidney \\ Blood Pressure Research}

\section{Kidney Blood Press Res 2013;38:196-204}

DOI: $10.1159 / 000355768$

Published online: April 08, 2014

(C) 2014 S. Karger AG, Basel

www.karger.com/kbr

25 Taniwaki H, Ishimura E, Tabata T, Tsujimoto Y, Shioi A, Shoji T, Inaba M, Inoue T, Nishizawa Y: Aortic calcification in haemodialysis patients with diabetes mellitus. Nephrol Dial Transplant 2005;20:24722478.

-26 Kidney Disease: Improving Global Outcomes CKDMBDWG: Kdigo clinical practice guideline for the diagnosis, evaluation, prevention, and treatment of chronic kidney disease-mineral and bone disorder (ckd-mbd). Kidney Int Suppl 2009:76:S1-130.

-27 Kaysen GA: The microinflammatory state in uremia: Causes and potential consequences. J Am Soc Nephrol 2001;12:1549-1557.

-28 London GM, Pannier B, Marchais SJ: Vascular calcifications, arterial aging and arterial remodeling in esrd. Blood Purif 2013;35:16-21.

29 Carr JJ, Register TC, Hsu FC, Lohman K, Lenchik L, Bowden DW, Langefeld CD, Xu J, Rich SS, Wagenknecht LE, Freedman BI: Calcified atherosclerotic plaque and bone mineral density in type 2 diabetes: The diabetes heart study. Bone 2008;42:43-52.

-30 Merjanian R, Budoff M, Adler S, Berman N, Mehrotra R: Coronary artery, aortic wall, and valvular calcification in nondialyzed individuals with type 2 diabetes and renal disease. Kidney Int 2003;64:263271.

31 Hu MC, Shi M, Zhang J, Quinones H, Griffith C, Kuro-o M, Moe OW: Klotho deficiency causes vascular calcification in chronic kidney disease. J Am Soc Nephrol 2011;22:124-136.

-32 Kuro-o M, Matsumura Y, Aizawa H, Kawaguchi H, Suga T, Utsugi T, Ohyama Y, Kurabayashi M, Kaname T, Kume E, Iwasaki H, Iida A, Shiraki-Iida T, Nishikawa S, Nagai R, Nabeshima YI: Mutation of the mouse klotho gene leads to a syndrome resembling ageing. Nature 1997;390:45-51.

33 Mirza MA, Hansen T, Johansson L, Ahlstrom H, Larsson A, Lind L, Larsson TE: Relationship between circulating fgf23 and total body atherosclerosis in the community. Nephrol Dial Transplant 2009;24:31253131.

-34 Schoppet M, Hofbauer LC, Brinskelle-Schmal N, Varennes A, Goudable J, Richard M, Hawa G, Chapurlat R, Szulc P: Serum level of the phosphaturic factor fgf23 is associated with abdominal aortic calcification in men: The strambo study. J Clin Endocrinol Metab 2012;97:E575-E583.

-35 London GM, Guerin AP, Marchais SJ, Metivier F, Pannier B, Adda H: Arterial media calcification in end-stage renal disease: Impact on all-cause and cardiovascular mortality. Nephrol Dial Transplant 2003;18:17311740 .

36 Vattikuti R, Towler DA: Osteogenic regulation of vascular calcification: An early perspective. Am J Physiol Endocrinol Metab 2004;286:E686-E696. 